\title{
Influence of Utility Tunnel on the Lower Part of the Existing Double-Track Shield Tunnel in Loess Soil
}

\author{
Min Yang $\mathbb{D}^{D}$, Hongru Li $\mathbb{D}^{D}$, Ning Li, and Shun Yang \\ Institute of Geotechnical Engineering, Xi'an University of Technology, Xi'an 710048, China \\ Correspondence should be addressed to Hongru Li; lhrbj@xaut.edu.cn
}

Received 2 April 2021; Accepted 11 July 2021; Published 24 July 2021

Academic Editor: Xianjie Hao

Copyright (C) 2021 Min Yang et al. This is an open access article distributed under the Creative Commons Attribution License, which permits unrestricted use, distribution, and reproduction in any medium, provided the original work is properly cited.

\begin{abstract}
The interaction between the double-track shield tunnel and the integrated pipe gallery is complex, and there is still a lack of systematic research. Based on the numerical simulation of the Xi'an case, this paper studies the influence of the construction of the integrated pipe gallery on the deformation characteristics of the existing double-line subway tunnels with different buried depths and clear distances and finds the safe buried depth and clear distance of the tunnel. The results indicated that, in the loess area, the maximum deformation of the existing subway has a linear and inverse relationship with the buried depth and spacing, respectively. Increasing the buried depth can reduce the impact of the upper construction disturbance more than increasing the clear distance ratio. Moreove, under the design conditions of constructing a utility tunnel by the open-cut method, when the buried depth of the tunnel is $4.5 \mathrm{D}$ and the spacing is greater than $4.5 \mathrm{D}$, or the buried depth is $5.0 \mathrm{D}$ and the spacing is greater than $2.5 \mathrm{D}$, the combination of subway tunnels can meet the deformation control standards.
\end{abstract}

\section{Introduction}

Nowadays, cities are developing at a fast pace and more and more underground buildings are being built. The construction of underground structures will inevitably lead to the change of stress field and displacement field, which will greatly affect the stability of existing underground structures $[1-5]$. How to reduce the influence between the lines will be an urgent problem to be solved in the future underground building construction. Previous research is mostly focused on the interaction between tunnels and foundation or existing tunnels [6-12]. However, with the development of the utility tunnel, it is urgent to study the influence of the excavation of the utility tunnel on the stability of the existing subway.

In order to improve the safety and maintainability of tunnels and pipelines, more and more researches on the interaction between tunnels and pipelines have been conducted [13-18]. However, most previous studies have chosen to simplify the duct-to-pipe interaction as a twodimensional problem. These include several analytical solutions for estimating pipeline response to tunneling
[13, 19-21]. Since these previous studies have simplified the tunnel-pipe interaction as a two-dimensional problem, it is impossible to determine this three-dimensional problem. In addition to the analysis solutions, a series of model tests and numerical simulations were performed to provide more information about the main mechanisms controlling the soil-pipe interaction caused by tunneling $[18,22-25]$.

In previous studies, pipes and tunnels are usually set perpendicular to each other. However, in reality, the pipe can intersect the tunnel at any angle $[14,17,19,20,21,23,25,26-28]$. When the existing tunnel and integrated pipe gallery are parallel to each other up and down, the excavation of the integrated pipe gallery will affect the entire existing tunnel. This problem needs to be simulated using a three-dimensional model. Aiming at the parallel phenomenon of utility tunnel and subway tunnel, [29] established a three-dimensional model that studied the numerical simulation of the influence of shield tunnel threedimensional dynamic construction process with different support pressures on the comprehensive pipe gallery in the loess area of Xi'an. However, there is no research on the 
impact of the excavation of the utility tunnel on the existing subway tunnels. Therefore, it is particularly important to simulate the influence of utility tunnel construction on shield tunnel by numerical method.

Based on loess in the Xi'an, this paper establishes a numerical model to investigate the influences of pipe gallery tunnel excavation on the lower part of the existing tunnel. It simulates the construction of comprehensive pipe gallery by the open-cut method over an existing subway tunnel under different combinations of cover span and net distance ratios. It obtains the scope of influence of the excavation of the comprehensive pipe gallery on the tunnel, which provides reference for the design and construction of similar projects.

\section{General Situation of Tunnel and Utility Tunnel}

The Metro Line 2 (ML2) tunnel is a double-track tunnel with parallel left and right sides in Xi'an. The support method of existing tunnel is prefabricated C50 reinforced concrete segments with a width and thickness of $1.5 \mathrm{~m}$ and $300 \mathrm{~mm}$, respectively. The outer diameter of segment is $6.0 \mathrm{~m}$. The connection between segments adopts bent bolts.

Combined with a utility tunnel project in $\mathrm{Xi}$ 'an, it is planned to build the utility tunnel on the lower part of the existing tunnel that is located in ML2 in operation in Xi'an. The relative position of a section tunnel and the pipe gallery is shown in Figure 1.

It can be seen from the previously mentioned crosssection of the relative position between the pipe gallery and the tunnel that the comprehensive pipe gallery is composed of three storehouses, which is natural tank, comprehend tank, and power tank from left to right. Their widths are, respectively, $2.1 \mathrm{~m}, 3.3 \mathrm{~m}$, and $2.3 \mathrm{~m}$. Their heights are all $2.6 \mathrm{~m}$. The sizes of the left and right hatches of the pipe gallery are not symmetrical, which is a typical unsymmetrical three-storehouse comprehensive pipe gallery. The structure of the utility tunnel is a rectangular structure surrounded by reinforced concrete roof, side wall, and floor. The side wall is called longitudinal structure, while the roof and floor are called horizontal members. The schematic diagram of cross section of pipe gallery is shown in Figure 2.

The construction of the utility tunnel adopts cut-andcover method. Its reinforcement form adopts slope and soil nail wall. The excavation is divided into five layers. The first and second excavation depths are $2.0 \mathrm{~m}$. The third and fourth excavation depths are $1.5 \mathrm{~m}$. The excavation depth of the last layer is $0.3 \mathrm{~m}$. After the excavation, shotcrete with mesh of C20 concrete is applied in time, and then, soil nails are applied. The soil nails are made of HRB400 steel bars with a diameter of $14 \mathrm{~mm}$, vertical spacing of $1.5 \mathrm{~m}$, and longitudinal separation of $1.0 \mathrm{~m}$. The thickness of sprayed concrete is $60 \mathrm{~mm}$. The cushion is made of $\mathrm{C} 15$ concrete. The utility tunnel structure is made of C35 concrete. Since the left and right support and treatment of the utility tunnel are the same, only the left half of the utility tunnel is shown in Figure 3.

\section{Three-Dimensional Numerical Model}

3.1. Numerical Scheme. The subway tunnel is an existing building, and a comprehensive pipe gallery will be built in the upper soil layer. For convenient description, introducing two concepts here, the cover span ratio $(H / D)$ is the ratio of the overburden layer thickness $(H)$ on the subway tunnel to the maximum span of the tunnel cross section, and the distance span ratio $(I / D)$ is the net distance $(I)$ between the two tunnels and the maximum span of the tunnel crosssection ratio for the two-lane tunnel. For the shield tunnel subway tunnel project, $D$ is the outer diameter of the segment.

In view of this actual situation, the model design conditions are combined according to the span ratio and the net ratio. The span ratio is $3,3.5,4,4.5$, and 5. The net ratio is 2.5, $3,3.5,4,4.5$, and 5 . There are 26 working conditions in total. The specific working conditions are shown in Table 1.

3.2. Material Model and Parameters. According to the soil properties, the soil layers within the buried depth of the tunnel section can be roughly divided into plain fill, neoloess, paleosol, and silty clay. The thickness of the soil layers is as follows: plain fill thickness is $3.0 \mathrm{~m}$, neoloess thickness is $4.0 \mathrm{~m}$, paleosol thickness is $3.0 \mathrm{~m}$, and the remaining soil layers can be considered as silty clay. According to different test methods, compression modulus is recommended for one-dimensional compression in soil simulation analysis. In case of three-dimensional deformation, modulus of deformation is recommended. In case of elastic deformation or initial deformation, elastic modulus is used [24]. So, the deformation modulus is as one of the soil parameters. The parameters required for the numerical simulation were based on the relevant literature [30-35], as shown in Table 2. The corresponding structures of tunnel and utility tunnel are simplified as elastic models. The specific parameters are selected according to the "Code for Design of Concrete Structures" [36] and the "Code for Design of Building Foundations" [37]. The specific parameters are shown in Table 3.

3.3. FEM Model. The numerical simulation software ABAQUS is used to simulate each scheme. It takes the numerical model of scheme 1 as an example. A three-dimensional model is established to investigate the double-tube parallel tunnels underneath deformation due to the construction of utility tunnels. The detailed model of the finite element model is shown in Figure 4. The model is $120 \mathrm{~m}$ in length, $90 \mathrm{~m}$ in width, and $50 \mathrm{~m}$ in depth. According to the actual geological conditions of Xi'an in China, the backfilling soil layer of pipe gallery is (1), and the stratum is (2) (5) from top to bottom. For the boundary conditions of the model, all four vertical sides restrain movement in the horizontal direction, the bottom boundary of the mesh restrains movement in the vertical and horizontal direction, and the top boundary is freedom to displace.

The simplified treatment of the model is as follows:

(1) Finite element method of linear elastic model has been used to calculate each structure of the utility tunnel and the shield tunnel. 


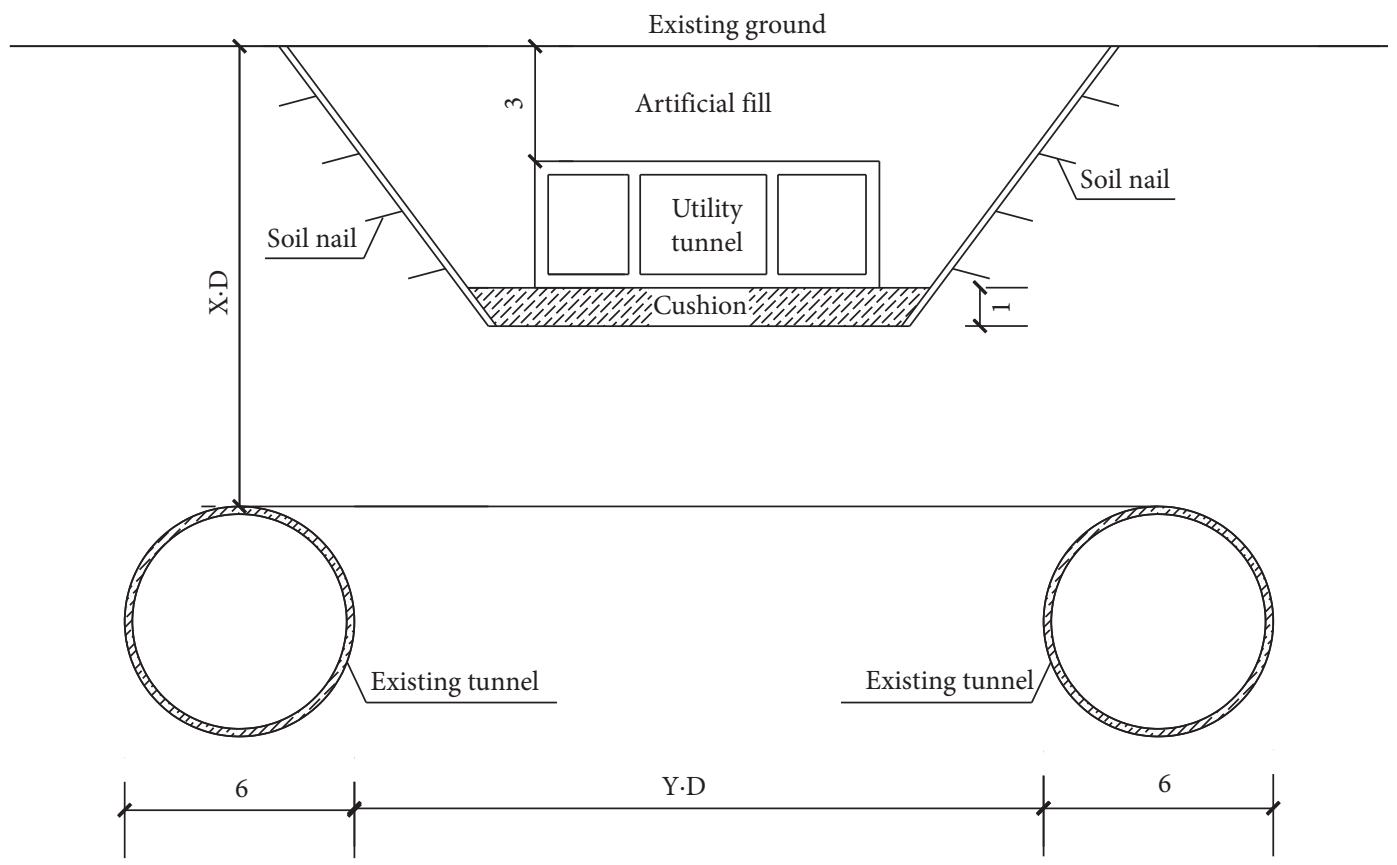

FIgURE 1: Sketch of relative position of utility tunnel and metro tunnel (unit: $\mathrm{m}$ ). $D$ represents the diameter of the tunnel.

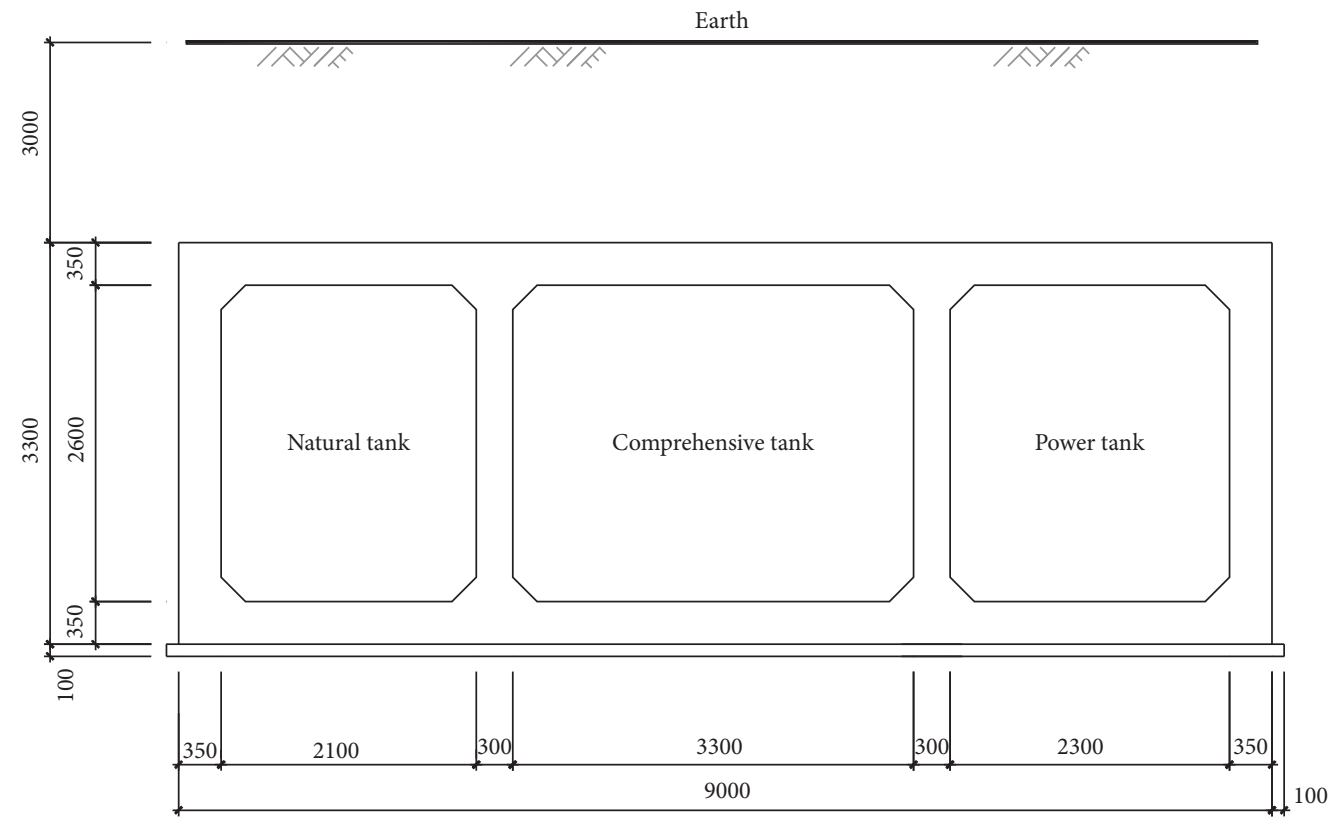

FIgURE 2: Schematic diagram of cross section of pipe gallery (unit: $\mathrm{mm}$ ).

(2) The construction process of the utility tunnel is simulated without regard for the consolidation settlement of the backfill in the later period.

(3) Regarding the tunnel segment as a whole, the splicing seams of segment is not considered.

(4) The tunnel grouting process is simplified, and the synchronous grouting range is taken as the six-ring range of shield tail segment without regard for the midterm grouting layer strength. Each ring of segment is $1.5 \mathrm{~m}$.
(5) The taper of shield machine and the friction between shield machine and soil are not considered in the simulation.

The simulation process was divided into three stages: (i) ground stress equilibration under the gravity; (ii) excavation of the existing shield tunnels; (iii) excavation of the utility tunnel on the lower part of the existing double-track shield tunnel. This paper focuses on the effect of the third stage. After the completion of the first and second stages, the displacement of the soils and structures was reset to zero. Therefore, the 


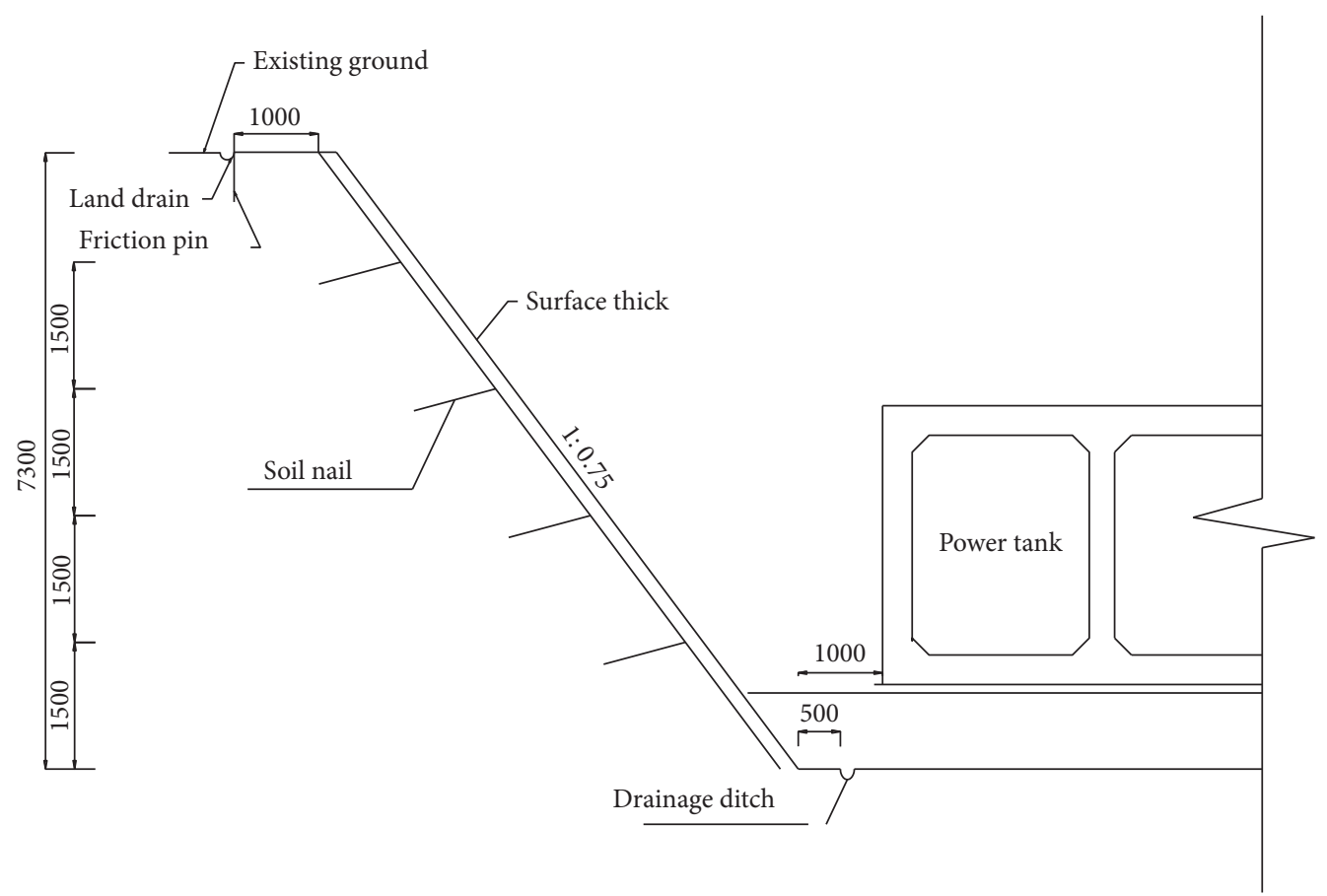

FIGURE 3: Schematic diagram of the left half of the utility tunnel (unit: $\mathrm{mm}$ ).

TABle 1: Model working condition statistics.

\begin{tabular}{lcc}
\hline Condition & $H / D$ & $I / D$ \\
\hline 1 & 3 & 3 \\
2 & 3 & 3.5 \\
3 & 3 & 4 \\
4 & 3 & 4.5 \\
5 & 3 & 5 \\
6 & 3.5 & 3 \\
7 & 3.5 & 3.5 \\
8 & 3.5 & 4 \\
9 & 3.5 & 4.5 \\
10 & 3.5 & 5 \\
11 & 4 & 3 \\
12 & 4 & 3.5 \\
13 & 4 & 4 \\
14 & 4 & 4.5 \\
15 & 4 & 5 \\
16 & 4.5 & 3 \\
17 & 4.5 & 3.5 \\
18 & 4.5 & 4 \\
19 & 4.5 & 4.5 \\
20 & 4.5 & 5 \\
21 & 5 & 2.5 \\
22 & 5 & 3 \\
23 & 5.5 \\
24 & 5 & 4 \\
25 & 5 & 4.5 \\
26 & 5 & 5 \\
\hline
\end{tabular}

calculation of the deformation of the existing tunnel is actually the incremental deformation caused by the excavation of the new utility tunnel.
3.4. Arrangement of Subway Tunnel Monitoring Points. Since the structure of the integrated pipe gallery is asymmetric, it is not only concerned with the deformation of a single tunnel. For better analysis, it is necessary to set monitoring points on both the left and right lines.

The section of the monitoring point is selected as the 15 th, 30th, and 45th ring of the tunnel. That is, the longitudinal length of the model tunnel is $22.5 \mathrm{~m}, 45 \mathrm{~m}$, and $67.5 \mathrm{~m}$. Eight monitoring points are arranged at the monitoring section of the tunnel. The point number gives the left and right lines of the 30-ring monitoring points, as shown in Figure 5. The location of the monitoring points in the model is shown in Figure 6.

\section{Analysis of the Impact of Comprehensive Pipe Gallery Excavation on Existing Subway Tunnels}

The relevant deformation standard of the subway tunnel of degree II level of magnitude of tunnel is the benchmark. For the subway tunnel structure deformation control standard, the maximum subsidence is $-10 \mathrm{~mm}$, the maximum uplift is $5 \mathrm{~mm}$, and the maximum horizontal displacement is $4 \mathrm{~mm}$.

\subsection{Displacement Analysis of Existing Tunnel Monitoring Points in Each Working Condition}

4.1.1. Vertical Displacement Analysis of Monitoring Points. Due to the large amount of data, only the monitoring points of the 30-section monitoring section on the left line were selected for analysis in each case to save space. This article only gives the vertical displacement maps of the monitoring 
TABLE 2: Soil basic physical property index.

\begin{tabular}{|c|c|c|c|c|c|c|c|c|c|}
\hline Soil layer & $\gamma\left(\mathrm{kN} / \mathrm{m}^{3}\right)$ & $E_{0}(\mathrm{MPa})$ & $v$ & $\beta$ & $d$ & $\lambda$ & $k$ & $e_{0}$ & $M$ \\
\hline (1) 1-1 artificial fill & 18.1 & 4.3 & 0.28 & 20.24 & 30.99 & - & - & - & - \\
\hline (2) 1-2 plain fill & 17 & 4 & 0.33 & 32.94 & 67.57 & - & - & - & - \\
\hline (3) $3-1-3$ neoloess & 18.3 & 6 & 0.33 & - & - & 0.10206 & 0.00912 & 0.866 & 0.77 \\
\hline (4) 3-2-2 paleosol & 18.9 & 8 & 0.31 & - & - & 0.07687 & 0.00782 & 0.756 & 0.69 \\
\hline (5) 4-4 silty clay & 20.1 & 13 & 0.3 & - & - & 0.06514 & 0.00782 & 0.64 & 0.77 \\
\hline
\end{tabular}

$\gamma$ is the soil bulk density. $E_{0}$ is the deformation modulus. $\nu$ is Poisson's ratio. $\beta$ is the internal friction angle. $d$ is the cohesive strength. $\lambda$ is the logarithm of plastic bulk modulus. $k$ is the logarithm of bulk modulus of elasticity. $e_{0}$ is the initial void ratio of soil. $M$ is the slope of CSL line.

TABLE 3: Parameters of structures of metro tunnel and utility tunnel.

\begin{tabular}{lcccc}
\hline Name & Bulk density $\left(\mathrm{kN} / \mathrm{m}^{3}\right)$ & Elasticity modulus $(\mathrm{MPa})$ & Poisson's ratio & Thickness $(\mathrm{m})$ \\
\hline Shield & 463.84 & $2.10 E+05$ & 0.30 & 0.20 \\
Segment & 25 & $2.84 E+04$ & 0.30 \\
Grouting (early) & 23 & 0.9 & 0.2 & 0.3 \\
Grouting (late) & 23 & 400 & 0.2 & - \\
Soil-nailed wall & 22 & $2.18 E+04$ & 0.3 \\
Soil nailing & 78.5 & $2.00 E+05$ & 0.2 \\
Cushion & 23 & $2.60 E+04$ & 0.2 \\
Corridor & 25 & $3.15 E+04$ & - \\
\hline
\end{tabular}

"-" means that the grouting layer completely fills the gap at the shield tail, without a fixed thickness.

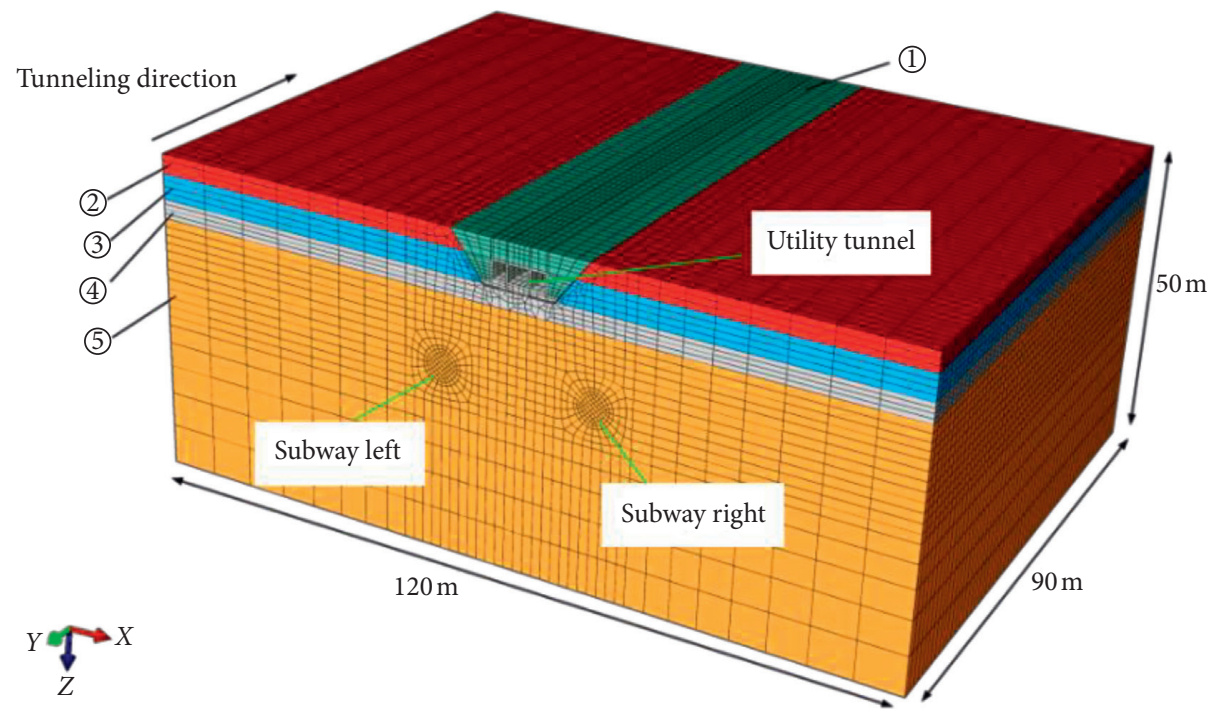

FIGURE 4: Numerical model of engineering.

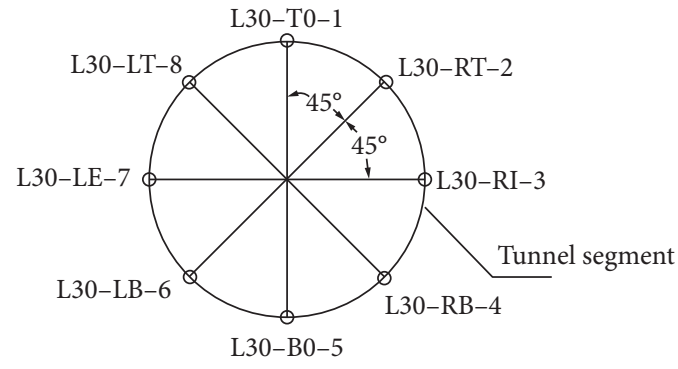

(a)

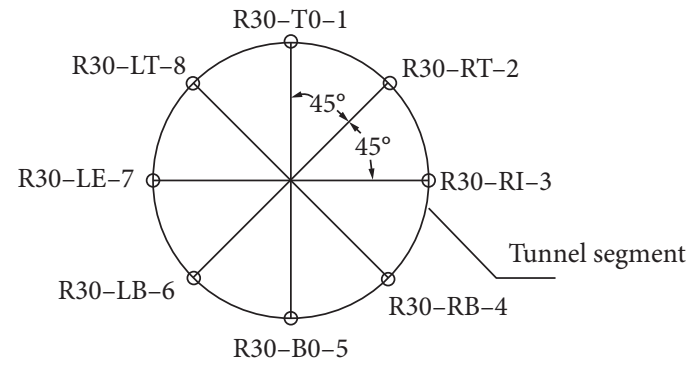

(b)

FIGURE 5: Monitoring points arrangement of each monitoring cross-section. (a) The 30th ring monitoring point on the left line. (b) The 30th ring monitoring point on the right line. 


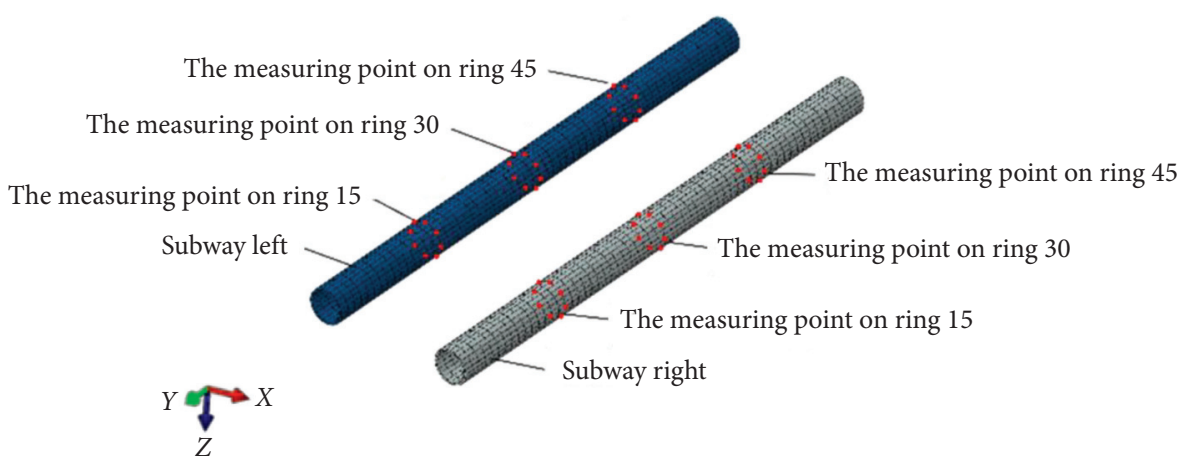

FIGURE 6: Monitoring cross-section arrangement.

points under conditions $1,5,21$, and 26, as shown in Figures 7 and 8 . Positive sign represents uplift, and negative sign represents subsidence in the Figures 7 and 8 . Here, the load step is supplemented as follows. The excavation of the utility tunnel is divided into five layers. The corresponding load step of initial stress calculation is 0 . The first, second, third, and fourth excavations correspond to load steps 1, 2, 3, 4 , respectively. The cushion construction that is the fifth excavation corresponds to load step 5. The construction of pipe gallery corresponds to load step 6 . The soil is backfilled to the top of the pipe gallery according to load step 7. After backfilling, it corresponds to load step 8 .

It can be seen from Figure 7 that the maximum peak of uplift appears at the right spandrel (L30-RT-2), which is $10.89 \mathrm{~mm}$ in case 1 . The minimum peak appears at the left spandrel (L30-LT-8), which is $7.25 \mathrm{~mm}$ in case 1 . The maximum value of the final displacement appears at the right spandrel (L30-RB-4), which is $1.45 \mathrm{~mm}$, and the minimum value of the final displacement appears at the left spandrel (L30-LT-8), which is $0.34 \mathrm{~mm}$. In case 5 , the maximum peak of uplift that is $7.33 \mathrm{~mm}$ appears at the right arch foot (L30-RB-4), the minimum value of uplift that is $3.85 \mathrm{~mm}$ appears at the left arch shoulder (L30-LT-8), the maximum value of the final displacement that is $1.03 \mathrm{~mm}$ appears at the right arch foot (L30-RB-4), and the minimum value of the final displacement that is $-0.04 \mathrm{~mm}$ appears at the left arch shoulder (L30-LT-8). With the increase of the distance between the subway tunnel and the pipe gallery, the maximum peak point will move from the upper part of the tunnel near the construction to the lower part of the tunnel. Moreover, the positions of the minimum peak value and the minimum value of the final value remain unchanged.

It can be seen from Figure 8 that the maximum peak of uplift appears at the vault (L30-TO-1), which is $4.92 \mathrm{~mm}$ in case 21 . The minimum peak appears at the arch bottom (L30BO-5), which is $3.52 \mathrm{~mm}$ in case 21 . The maximum value of the final displacement appears at the right arch foot (L30$\mathrm{RB}-4$ ), which is $0.57 \mathrm{~mm}$. The minimum value of the final displacement appears at the left shoulder span (L30-LT-8), which is $-0.09 \mathrm{~mm}$ in case 21 . In case 26 , the maximum peak of uplift that is $3.62 \mathrm{~mm}$ appears at the right arch foot (L30$\mathrm{RB}-4)$, the minimum value of uplift that is $1.94 \mathrm{~mm}$ appears at the left arch shoulder (L30-LT-8), the maximum value of the final displacement that is $0.55 \mathrm{~mm}$ appears at the right arch foot (L30-RB-4), and the minimum value of the final displacement that is $-0.29 \mathrm{~mm}$ appears at the left arch shoulder (L30-LT-8). With the increase of the distance between the subway tunnel and the pipe gallery, the maximum peak point will move from the upper part of the tunnel near the construction to the lower part of the tunnel. Moreover the positions of the minimum peak value and the minimum value of the final value remain unchanged.

It can be seen from Figures 7 and 8 that each working condition shows that the floating increment is positive in the off-load period, and each working condition shows that the floating increment is negative in the loading process. In the two stages, the floating increment value of each measuring point is different. In addition, as the distance between the tunnel and the integrated pipeline gallery increases under various working conditions, the impact of the construction disturbance on the subway tunnel will become less and less, which shows that the floating value is getting smaller and smaller. With the increase of the distance between the subway tunnel and the pipe gallery, the maximum peak point will move from the upper part of the tunnel near the construction to the lower part of the tunnel. Moreover, the positions of the minimum peak value and the minimum value of the final value remain unchanged.

On all these counts, under the condition of keeping the $H / D$ constant, the peak maximum point of the uplift will gradually move from the upper part of the tunnel near the construction to the lower part of the tunnel with the increase of $I / D$. However, with the increase of $H / D$, the maximum value of uplift peak does not move when $I / D$ is kept constant.

The maximum peak value of the vertical displacement, the minimum peak value of the vertical displacement, the maximum value of the final vertical displacement, and the minimum value of the final vertical displacement of each working condition are organized as shown in Table 4.

The maximum vertical displacement peak of working condition 1 is the largest $(10.89 \mathrm{~mm})$ in each working condition, and that of working condition 26 is the smallest $(3.62 \mathrm{~mm})$ in Table 5. When $H / D$ is constant, the maximum vertical displacement peak decreases with the increase of $I / D$. When $H / D$ is constant, the minimum value of vertical displacement peak decreases with the increase of $I / D$. After the backfill of the pipe gallery is completed, the final vertical displacement in each 


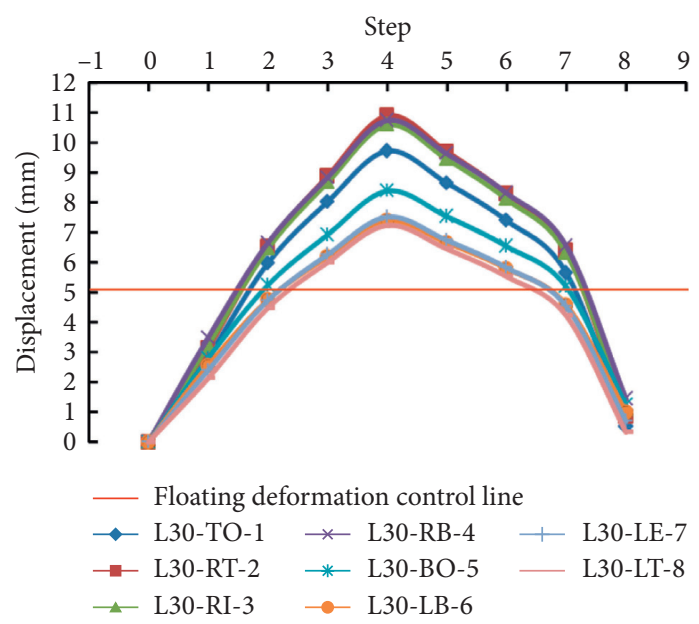

(a)

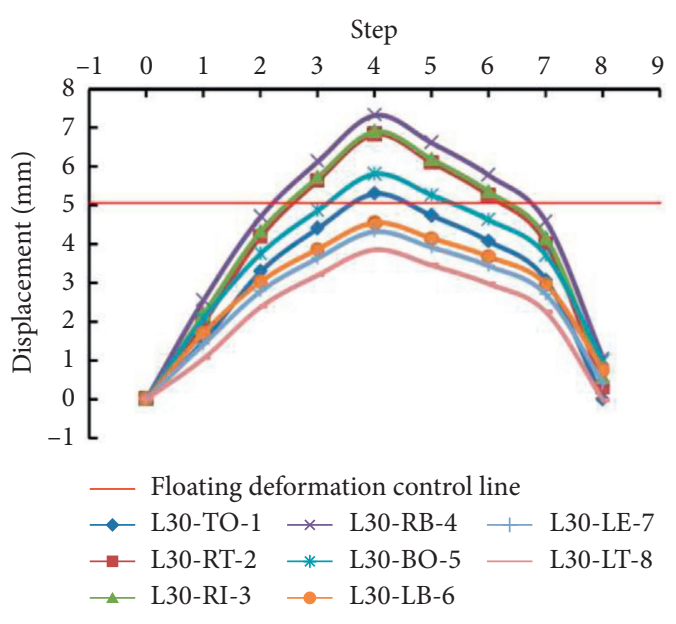

(b)

Figure 7: The vertical displacement of each monitoring points of each case when $H / D$ is 3 . (a) Working condition $1(I / D=3)$ vertical displacement of monitoring point. (b) Working condition $5(I / D=5)$ vertical displacement of monitoring point.

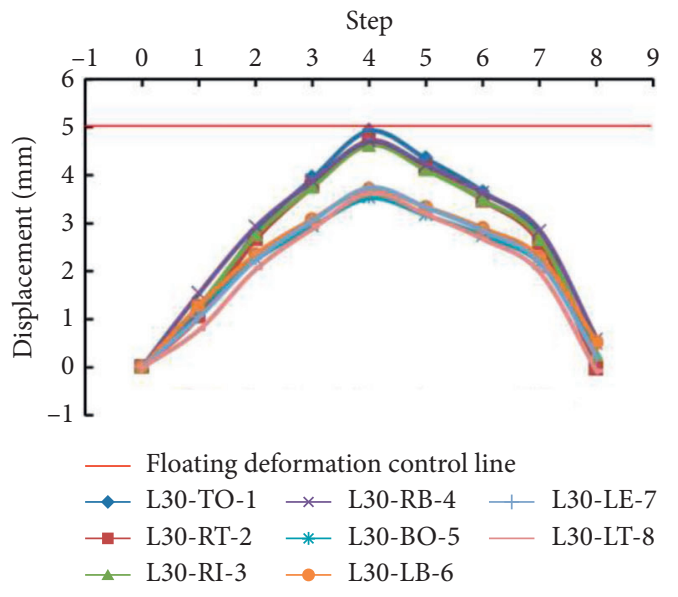

(a)

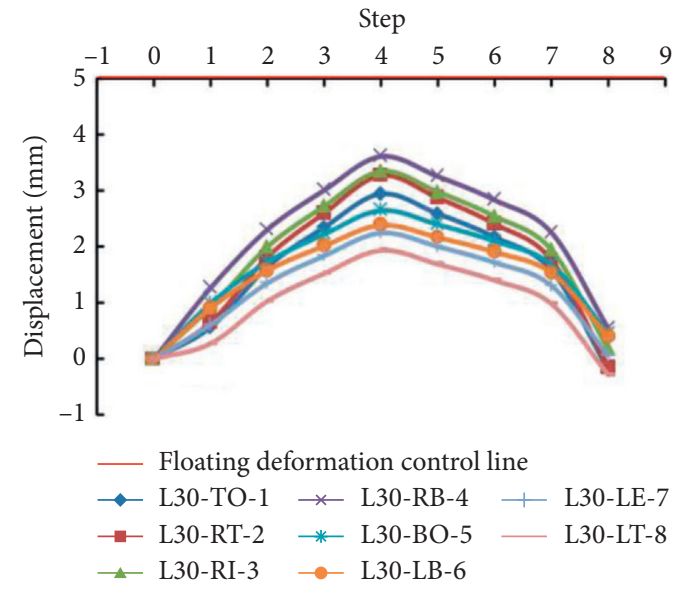

(b)

Figure 8: The vertical displacement of each monitoring point of each case when $H / D$ is 5 . (a) Working condition $21(I / D=2.5)$ vertical displacement of monitoring point. (b) Working condition $26(I / D=5)$ vertical displacement of monitoring point.

working condition is small. In the actual project, if there is a safety problem in the existing tunnel during the excavation stage of the integrated pipe gallery, other measures will be taken to remedy it. The actual stratum conditions of the pipe gallery pouring and backfilling will not be the same as the simulation situation in this paper.

Therefore, it is necessary to pay more attention to the maximum vertical displacement peak. According to the maximum vertical displacement peak of each working condition, linear regression is shown in Figure 9.

It can be seen from Figure 9 that $H / D$ and $I / D$ are highly correlated with the maximum vertical deformation respectively for $R^{2}$ greater than 0.98 . When the H/D is constant (Figure 9(a)), $I / D$ has a linear relationship with the maximum vertical deformation. The larger the $I / D$, the smaller the maximum vertical deformation. As the $H / D$ increases, the fitting line slope gradually becomes larger, and the influence of $I / D$ on the maximum vertical deformation will be smaller. When $I / D$ is constant (Figure 9(b)), H/D has a linear relationship with the maximum vertical deformation. The larger the $H / D$, the smaller the maximum vertical deformation. As $I / D$ increases, the fitting line slope gradually becomes larger, and the influence of $H / D$ on the maximum vertical deformation will be smaller. It can be seen from the two figures that the maximum vertical deformation is within the control range when $H / D$ is 5 . The two figures can show that the maximum vertical deformation is within the control range when $H / D$ is 5 and $I / D$ is variation. In addition, by the fitting line slope in the two figures, it can be found that $H / D$ has a greater influence on the maximum vertical deformation than $I / D$. Increasing the buried depth can reduce the construction disturbance more than increasing the net distance. 
TABle 4: Statistics of vertical displacement of each case.

\begin{tabular}{|c|c|c|c|c|c|c|}
\hline Condition & $\begin{array}{l}\text { The maximum } \\
\text { peak }(\mathrm{mm})\end{array}$ & $\begin{array}{l}\text { The minimum } \\
\text { peak }(\mathrm{mm})\end{array}$ & $\begin{array}{l}\text { The maximum value of the } \\
\text { final displacement }(\mathrm{mm})\end{array}$ & $\begin{array}{l}\text { The minimum value of the } \\
\text { final displacement }(\mathrm{mm})\end{array}$ & $H / D$ & $I / D$ \\
\hline 1 & 10.89 & 7.25 & 1.45 & 0.34 & 3 & 3 \\
\hline 2 & 9.91 & 6.29 & 1.34 & 0.22 & 3 & 3.5 \\
\hline 3 & 9.08 & 5.38 & 1.20 & 0.12 & 3 & 4 \\
\hline 4 & 8.20 & 4.61 & 1.12 & 0.04 & 3 & 4.5 \\
\hline 5 & 7.33 & 3.85 & 1.03 & -0.04 & 3 & 5 \\
\hline 6 & 8.97 & 6.15 & 1.26 & 0.22 & 3.5 & 3 \\
\hline 7 & 8.31 & 5.39 & 1.17 & 0.10 & 3.5 & 3.5 \\
\hline 8 & 7.68 & 4.67 & 1.09 & 0.01 & 3.5 & 4 \\
\hline 9 & 7.03 & 4.01 & 1.01 & -0.06 & 3.5 & 4.5 \\
\hline 10 & 6.39 & 3.38 & 0.93 & -0.14 & 3.5 & 5 \\
\hline 11 & 7.25 & 5.14 & 0.94 & 0.12 & 4 & 3 \\
\hline 12 & 6.79 & 4.58 & 0.93 & 0.08 & 4 & 3.5 \\
\hline 13 & 6.33 & 4.02 & 0.88 & 0.02 & 4 & 4 \\
\hline 14 & 5.85 & 3.43 & 0.81 & -0.12 & 4 & 4.5 \\
\hline 15 & 5.45 & 2.94 & 0.80 & -0.19 & 4 & 5 \\
\hline 16 & 5.78 & 4.19 & 0.75 & 0.02 & 4.5 & 3 \\
\hline 17 & 5.50 & 3.73 & 0.76 & -0.06 & 4.5 & 3.5 \\
\hline 18 & 5.16 & 3.24 & 0.69 & -0.18 & 4.5 & 4 \\
\hline 19 & 4.81 & 2.86 & 0.69 & -0.16 & 4.5 & 4.5 \\
\hline 20 & 4.46 & 2.44 & 0.66 & -0.22 & 4.5 & 5 \\
\hline 21 & 4.92 & 3.52 & 0.57 & -0.09 & 5 & 2.5 \\
\hline 22 & 4.54 & 3.28 & 0.57 & -0.13 & 5 & 3 \\
\hline 23 & 4.30 & 2.92 & 0.56 & -0.18 & 5 & 3.5 \\
\hline 24 & 4.07 & 2.58 & 0.55 & -0.23 & 5 & 4 \\
\hline 25 & 3.81 & 2.26 & 0.53 & -0.24 & 5 & 4.5 \\
\hline 26 & 3.62 & 1.94 & 0.55 & -0.29 & 5 & 5 \\
\hline
\end{tabular}

TABLE 5: Statistics of lateral displacement of each case.

\begin{tabular}{|c|c|c|c|c|c|c|}
\hline Condition & $\begin{array}{l}\text { The maximum } \\
\text { peak }(\mathrm{mm})\end{array}$ & $\begin{array}{l}\text { The minimum } \\
\text { peak }(\mathrm{mm})\end{array}$ & $\begin{array}{l}\text { The maximum value of } \\
\text { the final displacement }(\mathrm{mm})\end{array}$ & $\begin{array}{l}\text { The minimum value of } \\
\text { the final displacement }(\mathrm{mm})\end{array}$ & $H / D$ & $I / D$ \\
\hline 1 & 4.74 & 2.38 & 0.98 & 0.44 & 3 & 3 \\
\hline 2 & 4.73 & 2.79 & 1.03 & 0.47 & 3 & 3.5 \\
\hline 3 & 4.63 & 3.13 & 1.07 & 0.50 & 3 & 4 \\
\hline 4 & 4.66 & 3.26 & 1.15 & 0.53 & 3 & 4.5 \\
\hline 5 & 4.48 & 3.31 & 1.16 & 0.54 & 3 & 5 \\
\hline 6 & 4.39 & 1.90 & 0.93 & 0.33 & 3.5 & 3 \\
\hline 7 & 4.37 & 2.27 & 0.97 & 0.38 & 3.5 & 3.5 \\
\hline 8 & 4.35 & 2.60 & 1.02 & 0.44 & 3.5 & 4 \\
\hline 9 & 4.33 & 2.86 & 1.04 & 0.48 & 3.5 & 4.5 \\
\hline 10 & 4.30 & 3.00 & 1.10 & 0.49 & 3.5 & 5 \\
\hline 11 & 3.90 & 1.47 & 0.83 & 0.16 & 4 & 3 \\
\hline 12 & 3.93 & 1.84 & 0.87 & 0.26 & 4 & 3.5 \\
\hline 13 & 3.91 & 2.13 & 0.89 & 0.32 & 4 & 4 \\
\hline 14 & 3.87 & 2.39 & 0.87 & 0.37 & 4 & 4.5 \\
\hline 15 & 4.01 & 2.62 & 0.99 & 0.41 & 4 & 5 \\
\hline 16 & 3.61 & 1.20 & 0.83 & 0.09 & 4.5 & 3 \\
\hline 17 & 3.69 & 1.54 & 0.87 & 0.17 & 4.5 & 3.5 \\
\hline 18 & 3.69 & 1.76 & 0.84 & 0.15 & 4.5 & 4 \\
\hline 19 & 3.70 & 2.07 & 0.91 & 0.30 & 4.5 & 4.5 \\
\hline 20 & 3.68 & 2.30 & 0.93 & 0.36 & 4.5 & 5 \\
\hline 21 & 3.18 & 0.63 & 0.71 & -0.08 & 5 & 2.5 \\
\hline 22 & 3.33 & 0.97 & 0.79 & 0.01 & 5 & 3 \\
\hline 23 & 3.41 & 1.27 & 0.82 & 0.08 & 5 & 3.5 \\
\hline 24 & 3.40 & 1.48 & 0.79 & 0.08 & 5 & 4 \\
\hline 25 & 3.45 & 1.75 & 0.85 & 0.18 & 5 & 4.5 \\
\hline 26 & 3.50 & 1.96 & 0.91 & 0.22 & 5 & 5 \\
\hline
\end{tabular}




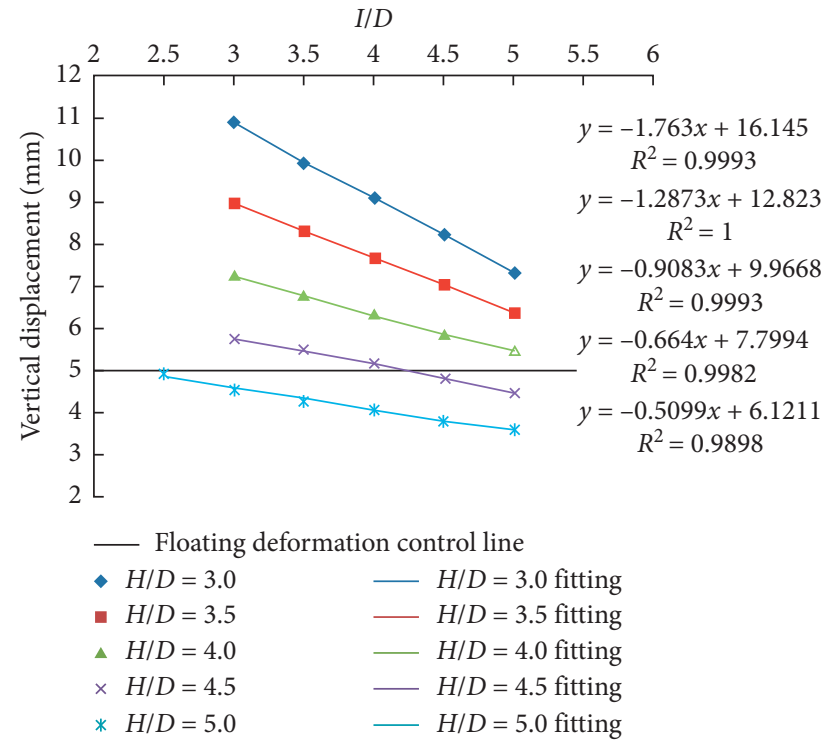

(a)

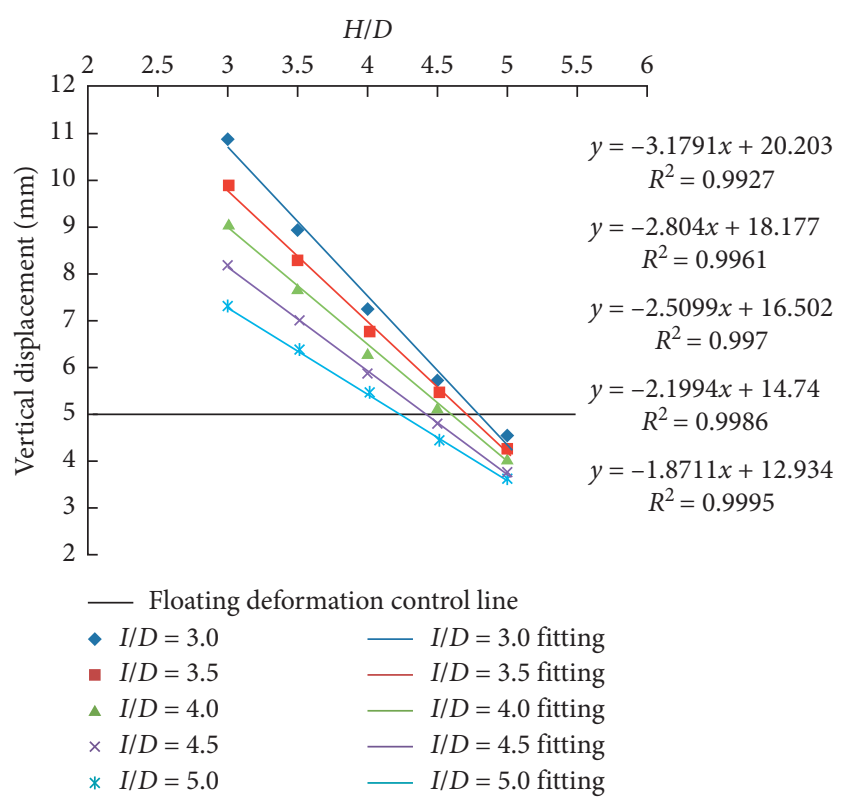

(b)

Figure 9: Variation of the maximum value of vertical deformation with $H / D$ and $I / D$ respectively. (a) Variation of the maximum vertical deformation of each working condition with $I / D$ under different $H / D$. (b) Variation of the maximum vertical deformation of each working condition with $H / D$ under different $I / D$.

4.1.2. Analysis of Lateral Displacement of Monitoring Points in Various Working Conditions. Due to the large amount of data, only the monitoring points of the 30-section monitoring section on the left line were selected for analysis in each case to save space.

Here, the maximum value of the peak value, minimum value of the peak value, maximum value of the final value, and minimum value of the final value of the lateral displacement of each working condition will be directly given. The statistics are shown in Table 5.

The maximum lateral displacement peak of working condition 1 is the largest $(4.74 \mathrm{~mm})$ in each working condition, and that of working condition 21 is the smallest $(3.18 \mathrm{~mm})$, as shown in Table 6 . The correlation between the maximum lateral displacement peak and $I / D$ has a certain relationship with $H / D$. When the minimum lateral displacement peak of each working condition is fixed at $H / D$, it will increase with the increase of $I / D$. After the backfill of the pipe gallery is completed, the final vertical displacement in each working condition is small. After the backfill of the pipe gallery is completed, the final lateral displacement in each working condition is small. It is necessary to pay more attention to the maximum displacement peak. According to the maximum displacement peak of each working condition, linear regression is shown in Figure 10.

In Figure $10(\mathrm{a})$, when $H / D$ is 4.0 and $4.5, R^{2}$ is 0.2341 and 0.478 , respectively, which indicates that $I / D$ has a little influence on the maximum lateral deformation. When $H / D$ is $3.0,3.5$, and $5.0, R^{2}$ is $0.7928,0.9934$, and 0.8619 , respectively, which indicates that $I / D$ is linear with the maximum value of lateral deformation. When $H$ /
$D$ is 3.0 and 3.5 , the maximum lateral deformation decreases with the increase of $I / D$. When $H / D$ is 5.0 , the maximum transverse deformation increases with the increase of $I / D$. When $I / D$ is constant (Figure $10(\mathrm{~b})$ ), $H / D$ has a linear relationship with the maximum lateral deformation for $R^{2}$ greater than 0.97 . The greater the $H / D$ is, the smaller the maximum lateral deformation is. Moreover, with the increase of $I / D$, the fitting line slope gradually becomes larger, which indicates that the influence of $H / D$ on the maximum lateral deformation will be smaller. In addition, from the fitting line slope in the two figures, it can be found that $H / D$ has a greater impact on the maximum lateral deformation than $I / D$. That is, increasing the buried depth can reduce construction disturbances more than increasing the clear distance.

In summary, according to Figures 9 and 10, when the buried depth of the tunnel is $4.5 \mathrm{D}$ and the spacing is greater than $4.5 \mathrm{D}$, or the buried depth is $5.0 \mathrm{D}$ and the spacing is greater than $2.5 \mathrm{D}$, the combination of subway tunnels can meet the deformation control standards.

4.2. Subsidiary Stress Analysis of Existing Tunnel. The monitoring points of the monitoring section of the 30th ring on the left line are selected for circumferential stress analysis. The statistics are shown in Table 6.

In Table 6, the maximum peak of the additional tension stresses of working condition 1 is the largest among all working conditions (3.32 $\mathrm{MPa})$, while that of working condition 26 is the smallest $(1.35 \mathrm{MPa})$. When the value of $H / D$ is constant, the maximum peak of the additional tension stresses decreases with the increase of 
TABLE 6: Statistics of circular additional pressure of each case.

\begin{tabular}{|c|c|c|c|c|c|c|}
\hline Condition & $\begin{array}{c}\text { The maximum peak of } \\
\text { the additional tension } \\
\text { stresses }(\mathrm{MPa})\end{array}$ & $\begin{array}{c}\text { The maximum peak of the } \\
\text { additional compression } \\
\text { stress }(\mathrm{MPa})\end{array}$ & $\begin{array}{c}\text { The maximum value of the } \\
\text { final additional tension } \\
\text { stresses }(\mathrm{MPa})\end{array}$ & $\begin{array}{l}\text { The maximum value of the } \\
\text { final additional compression } \\
\text { stresses (MPa) }\end{array}$ & $H / D$ & $I / D$ \\
\hline 1 & 3.32 & -2.72 & 0.501 & -0.511 & 3 & 3 \\
\hline 2 & 3.15 & -2.71 & 0.491 & -0.474 & 3 & 3.5 \\
\hline 3 & 2.95 & -2.56 & 0.480 & -0.416 & 3 & 4 \\
\hline 4 & 2.73 & -2.45 & 0.516 & -0.429 & 3 & 4.5 \\
\hline 5 & 2.45 & -2.24 & 0.506 & -0.401 & 3 & 5 \\
\hline 6 & 2.73 & -2.06 & 0.379 & -0.359 & 3.5 & 3 \\
\hline 7 & 2.65 & -2.13 & 0.375 & -0.360 & 3.5 & 3.5 \\
\hline 8 & 2.53 & -2.12 & 0.378 & -0.360 & 3.5 & 4 \\
\hline 9 & 2.38 & -2.07 & 0.386 & -0.366 & 3.5 & 4.5 \\
\hline 10 & 2.24 & -1.97 & 0.415 & -0.350 & 3.5 & 5 \\
\hline 11 & 2.40 & -1.58 & 0.290 & -0.259 & 4 & 3 \\
\hline 12 & 2.12 & -1.66 & 0.270 & -0.305 & 4 & 3.5 \\
\hline 13 & 2.03 & -1.71 & 0.233 & -0.332 & 4 & 4 \\
\hline 14 & 1.97 & -1.71 & 0.239 & -0.330 & 4 & 4.5 \\
\hline 15 & 1.92 & -1.61 & 0.278 & -0.253 & 4 & 5 \\
\hline 16 & 2.27 & -1.61 & 0.299 & -0.276 & 4.5 & 3 \\
\hline 17 & 2.04 & -1.34 & 0.273 & -0.249 & 4.5 & 3.5 \\
\hline 18 & 1.78 & -1.26 & 0.209 & -0.180 & 4.5 & 4 \\
\hline 19 & 1.65 & -1.33 & 0.221 & -0.243 & 4.5 & 4.5 \\
\hline 20 & 1.58 & -1.35 & 0.190 & -0.264 & 4.5 & 5 \\
\hline 21 & 2.28 & -1.75 & 0.286 & -0.279 & 5 & 2.5 \\
\hline 22 & 2.13 & -1.57 & 0.283 & -0.275 & 5 & 3 \\
\hline 23 & 1.94 & -1.36 & 0.259 & -0.251 & 5 & 3.5 \\
\hline 24 & 1.72 & -1.12 & 0.2 .13 & -0.197 & 5 & 4 \\
\hline 25 & 1.54 & -1.02 & 0.212 & -0.191 & 5 & 4.5 \\
\hline 26 & 1.35 & -1.04 & 0.188 & -0.187 & 5 & 5 \\
\hline
\end{tabular}

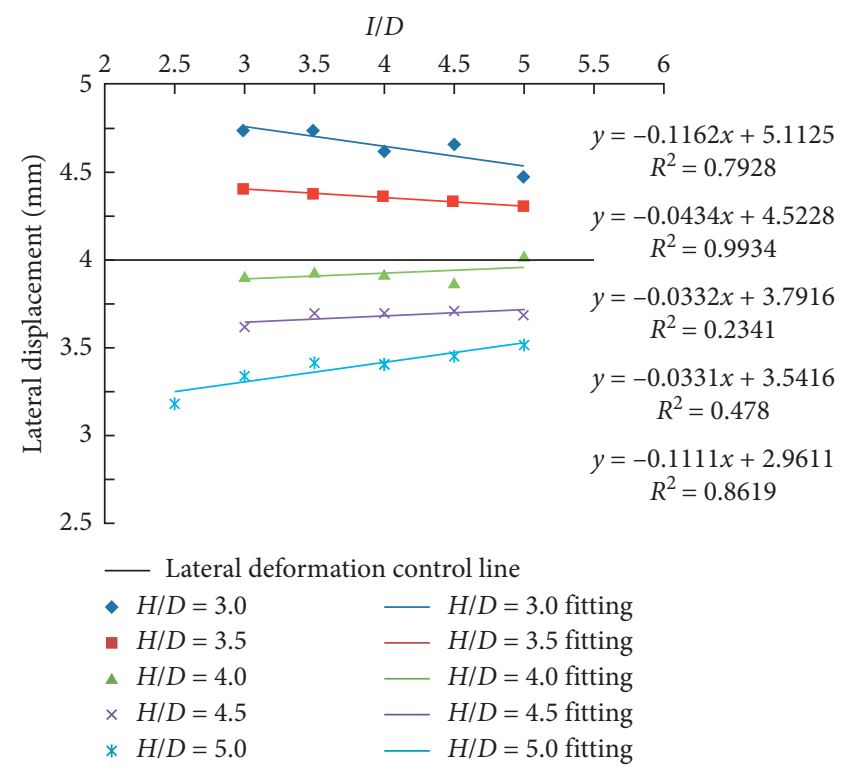

(a)

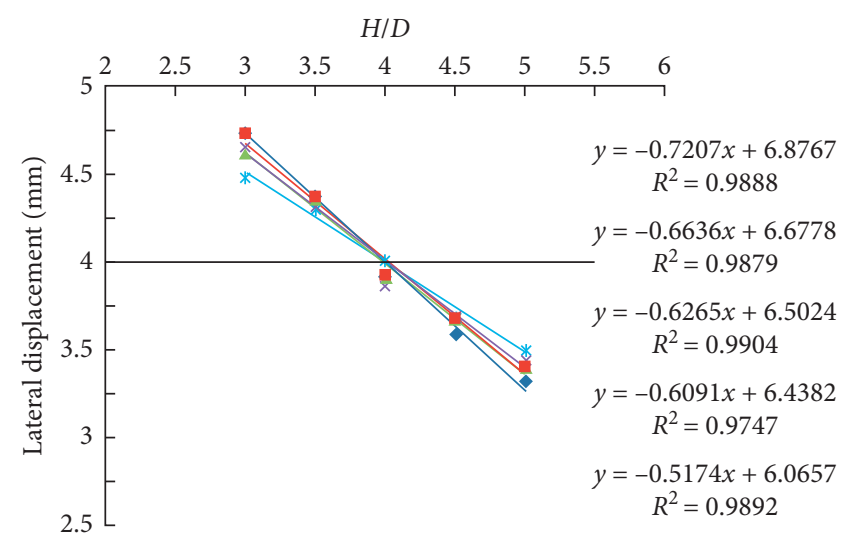

_ Lateral deformation control line
- $I / D=3.0$
$I / D=3.0$ fitting
- $I / D=3.5$
$\triangle I / D=4.0$
$\times I / D=4.5$
* $I / D=5.0$
- $I / D=3.5$ fitting
$I / D=4.0$ fitting
$-I / D=4.5$ fitting
$I / D=5.0$ fitting

(b)

FIGURE 10: Variation of the maximum value of lateral deformation with $H / D$ and $I / D$ respectively. (a) Variation of the maximum vertical deformation of each working condition with $I / D$ under different $H / D$. (b) Variation of the maximum vertical deformation of each working condition with $H / D$ under different $I / D$. 


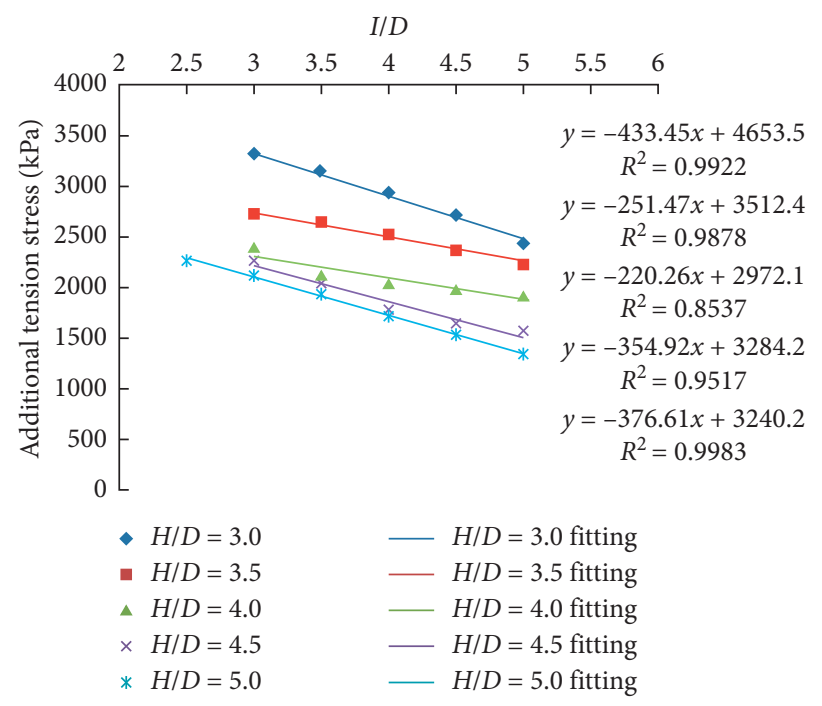

(a)

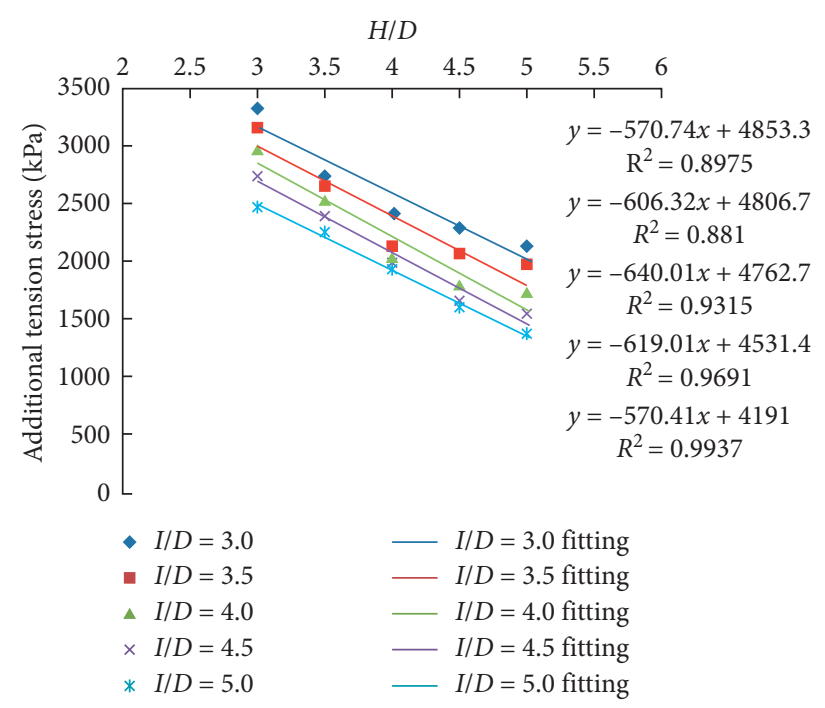

(b)

FIGURE 11: Variation of the maximum peak of additional tensile stress with $H / D$ and $I / D$, respectively. (a) Variation of the maximum peak of additional tensile stress with $I / D$ under different $H / D$. (b) Variation of the maximum peak of additional tensile stress with $H / D$ under different $I / D$ conditions.

$I / D$. The maximum peak of the additional compression stress of working condition 1 is the largest among all working conditions $(-2.72 \mathrm{MPa})$, while that of working condition 25 is the smallest $(-1.02 \mathrm{MPa})$. The correlation between the maximum peak of the additional compression stress of each working condition and the $I / D$ has a certain relationship with $H / D$.

After the completion of backfilling, the subsidiary stress absolute value of each working condition is within $0.51 \mathrm{MPa}$. In actual engineering, it is necessary to pay more attention to the tension of reinforced concrete segments. According to the maximum peak of the additional tension stresses of each working condition, linear regression is shown in Figure 11.

$H / D$ and $I / D$ are highly correlated with the maximum peak of the additional tension stresses, respectively, for $R^{2}$ greater than 0.85 in Figure 11. When the $H / D$ is constant (Figure 11(a)), $I / D$ has a linear relationship with the maximum peak of the additional tension stresses. The larger the $I / D$, the smaller the maximum peak of the additional tension stresses. When the $I / D$ is constant (Figure 11(b)), H/D has a linear relationship with the maximum peak of the additional tension stresses. The larger the $H / D$, the smaller the maximum peak of the additional tension stresses. In addition, from the fitting line slope in the two figures, it can be found that $H / D$ has a greater influence on the maximum peak of the additional tension stresses than $I / D$. Increasing the buried depth can reduce the construction disturbance more than increasing the net distance.

\section{Conclusions}

This paper investigates the influences of pipe gallery tunnel excavation undercrossing on the existing twin tunnels. It simulates the construction of comprehensive pipe gallery by the open-cut method over an existing subway tunnel under different combinations of cover span and net distance ratios. It analyzes the vertical displacement, lateral displacement, and additional stress of the segment during the construction process.

(1) The maximum peak of vertical displacement, lateral displacement, and additional stress of the pipe segments appear in the unloading stage of each working condition. The tunnel closer to the construction area in each working condition will be more disturbed. For the working condition with $H / D=3$ and $I / D=3$, the vertical displacement and lateral displacement have exceeded the deformation after being disturbed.

(2) The maximum vertical displacement has a linearly inverse relationship with the cover span and distance span ratios in each working condition. The maximum lateral displacement has a linearly inverse relationship with the cover span ratio. The maximum lateral displacement has different relativities with the distance span ratio under different cover span ratios. Increasing the buried depth can reduce construction disturbances more than increasing the clear distance. The maximum additional stresses have obvious linear inverse relationships with the cover span and distance span ratios.

(3) Under the design conditions of constructing a comprehensive pipe gallery by the open-cut method, when the buried depth of the tunnel is $4.5 \mathrm{D}$ and the spacing is greater than $4.5 \mathrm{D}$, or the buried depth is $5.0 \mathrm{D}$ and the spacing is greater than $2.5 \mathrm{D}$, the combination of subway tunnels can meet the deformation control standards. If it is necessary to build a comprehensive pipe gallery under a smaller cover span ratio or distance span ratio combination, 
other foundation pit excavation methods are required to ensure the safety of the subway tunnel.

\section{Data Availability}

The data used to support the findings of this study are included within the article.

\section{Conflicts of Interest}

The authors declare that they have no conflicts of interest.

\section{Acknowledgments}

This research was financially supported by the Xi'an University of Technology foundation (107/256211404), Loess Soil Mechanics and Engineering Key Laboratory of Shaanxi Province Foundation (13JS073), Natural Science Foundation of Shaanxi Province (2017JM5059), and National Natural Science Foundation of China (grant nos.: 11572246 and 51779207).

\section{References}

[1] R. P. Chen, J. Zhu, W. Liu, and X. W. Tang, "Ground movement induced by parallel EPB tunnels in silty soils," Tunnelling and Underground Space Technology, vol. 1, no. 26, pp. 163-171, 2011.

[2] R. P. Chen, L. J. Tang, D. S. Ling, and Y. M. Chen, "Face stability analysis of shallow shield tunnels in dry sandy ground using the discrete element method," Computers and Geotechnics, vol. 38, no. 2, pp. 187-195, 2011.

[3] R. Chen, J. Li, L. Kong, and L. Tang, "Experimental study on face instability of shield tunnel in sand," Tunnelling and Underground Space Technology, vol. 33, pp. 12-21, 2013.

[4] S. Ma, Y. Shao, Y. Liu, J. Jiang, and X. L. Fan, "Responses of pipeline to side-by-side twin tunnelling at different depths: $3 \mathrm{~d}$ centrifuge tests and numerical modelling," Tunnelling and Underground Space Technology, vol. 66, pp. 157-173, 2017.

[5] K. Soga, R. G. Laver, and Z. Li, "Long-term tunnel behaviour and ground movements after tunnelling in clayey soils," Underground Space, vol. 2, no. 3, pp. 149-167, 2017.

[6] V. Avgerinos, D. M. Potts, and J. R. Standing, "Numerical investigation of the effects of tunnelling on existing tunnels," Geotechnique, vol. 67, no. 9, pp. 808-822, 2017.

[7] J. Liu, T. Qi, and Z. Wu, "Analysis of ground movement due to metro station driven with enlarging shield tunnels under building and its parameters sensitivity analysis," Tunneling and Underground Space Technology, vol. 28, no. 8, pp. 287296, 2014

[8] M. Malek, H. Sereshteh, M. Mousivand et al., "An equivalent beam model for the analysis of tunnel-building interaction," Tunneling and Underground Space Technology, vol. 26, no. 9, pp. 524-533, 2011.

[9] C. W. W. Ng, K. Y. Fong, and H. L. Liu, "The effects of existing horseshoe-shaped tunnel sizes on circular crossing tunnel interactions: three-dimensional numerical analyses," Tunnelling and Underground Space Technology, vol. 77, pp. 68-79, 2018.

[10] R. E. Ranken and J. Ghaboussi, "Analysis of interaction between two parallel tunnels," Finite Element Method, vol. 34, no. 2, pp. 45-52, 1976.
[11] M. L. Yin, H. Jiang, Y. S. Jiang, Z. Y. Sun, and Q. L. Wu, "Effect of the excavation clearance of an under-crossing shield tunnel on existing shield tunnels," Tunnelling and Underground Space Technology, vol. 78, pp. 245-258, 2018.

[12] Z. Zhang and M. Huang, "Geotechnical influence on existing subway tunnels induced by multiline tunneling in Shanghai soft soil," Computers and Geotechnics, vol. 56, pp. 121-132, 2014.

[13] P. B. Attewell, J. Yeates, and A. R. Selby, Soil Movements Induced by Tunnelling and Their Effects on Pipelines and Structures, Blackie and Son Ltd., London, Scotland, 1986.

[14] A. Klar, T. E. B. Vorster, K. Soga, and R. J. Mair, "Soil-pipe interaction due to tunnelling: comparison between winkler and elastic continuum solutions," Géotechnique, vol. 55, no. 6, pp. 461-466, 2005a.

[15] A. Klar, T. E. Vorster, K. Soga, and R. Mair, "Elastoplastic solution for soil-pipe-tunnel interaction," Journal of Geotechnical and Geoenvironmental Engineering, vol. 133, no. 7, pp. 782-792, 2007.

[16] C. Lin, M. Huang, N. Farrokh, and Z. Liu, "Tunnelling-induced response of buried pipelines and their effects on ground settlements," Tunnelling and Underground Space Technology, vol. 96, pp. 103-193, 2020.

[17] T. E. B. Vorster, A. Klar, K. Soga, and R. J. Mair, "Estimating the effects of tunneling on existing pipelines," Journal of Geotechnical \& Geoenvironmental Engineering, vol. 131, no. 11, pp. 1399-1410, 2005.

[18] Y. Wang, J. Shi, and C. W. Ng, "Numerical modeling of tunneling effect on buried pipelines," Canadian Geotechnical Journal, vol. 48, no. 7, pp. 1125-1137, 2011a.

[19] A. Klar, T. Vorster, K. Soga, and R. Mair, "Continuum solution of soil-pipe-tunnel interaction including local failure," in Proceedings of the 11th International Conference of lacmag, pp. 687-694, ACM, Torino, Italy, March 2005.

[20] A. M. Marshall, A. Klar, and R. Mair, "Tunneling beneath buried pipes: view of soil strain and its effect on pipeline behavior," Journal of Geotechnical \& Geoenvironmental Engineering, vol. 136, no. 12, pp. 1664-1672, 2010.

[21] Y. Wang, Q. Wang, and K. Zhang, "Tunneling effect on underground pipelines a closed-form solution," in Proceedings of Geotechnical Challenges in Megacities, pp. 814-819, Moscow, Russia, June 2010.

[22] J. W. Shi, Y. Wang, and C. W. Ng, "Three-dimensional centrifuge modeling of ground and pipeline response to tunnel excavation," Journal of Geotechnical \& Geoenvironmental Engineering, vol. 142, no. 11, Article ID 04016054, 2016.

[23] Z. X. Wang, L. C. Miu, R. R. Wang, and H. Pan, "Model test study of vertical buried continuous pipelines displacements affected by tunnelling in sand," Rock Soil Mechanics, vol. 34, no. Supp.2, pp. 143-149, 2013.

[24] L. Wang, Study on Interaction Mechanism and Deformation Control Standard of Collapsible Loess Layer and Metro Structure, Chang'an university, Xi'an, Shaanxi, China, 2016.

[25] Y. T. Zhu, H. Zhang, Z. X. Zhang, X. Huang, and K. Liu, "Physical model test study of influence of advance of shield tunnel on adjacent underground pipelines," Rock and Soil Mechanics, vol. 37, no. Supp.2, pp. 151-160, 2016.

[26] A. Klar and A. M. Marshall, "Shell versus beam representation of pipes in the evaluation of tunneling effects on pipelines," Tunnelling and Underground Space Technology, vol. 23, no. 4, pp. 431-437, 2008. 
[27] A. Klar and A. Marshall, "Linear elastic tunnel pipeline interaction: the existence and consequence of volume loss equality," Geotechnique, vol. 65, no. 9, pp. 788-792, 2015.

[28] Y. Wang, Q. Wang, and K. Y. Zhang, "An analytical model for pipe-soil-tunneling interaction," Procedia Engineering, vol. 14, pp. 3127-3135, 2011b.

[29] M. Yang, H. Li, N. Li, and S. Yang, "Effect of subway excavation with different support pressures on existing utility tunnel in Xi'an loess," Advances in Civil Engineering, vol. 2020, Article ID 8818949, 2020.

[30] M. He, Z. Zhang, J. Zheng, F. Chen, and N. Li, "A new perspective on the constant $\mathrm{mi}$ of the hoek-brown failure criterion and a new model for determining the residual strength of rock," Rock Mechanics and Rock Engineering, vol. 53, no. 9, pp. 3953-3967, 2020.

[31] M. M. He, Z. Q. Zhang, J. Ren et al., "Deep convolutional neural network for fast determination of the rocks trength parameters using drilling data," International Journal of Rock Mechanics and Mining Sciences, vol. 123, Article ID 104084, 2019.

[32] M. M. He, Z. Q. Zhang, and N. Li, "Deep convolutional neural networks-based method for strength parameter prediction of jointed rock mass using drilling logging data," International Journal of Geomechanics, vol. 21, no. 7, 2021a.

[33] M. M. He, Z. Q. Zhang, J. W. Zhu, N. Li, G. F. Li, and Y.S. Chen, "Correlation between the rockburst proneness and friction characteristics of rock materials and a new method for rockburst proneness prediction: field demonstration," Journal of Petroleum Science and Engineering, vol. 205, Article ID 108997, 2021b.

[34] G. Tian, Study on Engineering Characteristics of Loess in Xi'an Metro Line 2, Xi'an University of Technology, Xi'an, Shaanxi, China, 2008.

[35] C. Zhu, Study on Ground Deformation Law Caused by Subway Shield Construction in Xi'an Loess Soil, Xian university of science and technology, Xi'an, Shaanxi, China, 2009.

[36] 50010-2010, Ministry of Housing and Urban-Rural Development of the People's Republic of China. GB50010-2010 Code for Design of concrete Structures, China Architecture and Building Press, Beijing, China, 2015, in Chinese.

[37] Gb50007-2011, Ministry of Housing and Urban-Rural Development of the People's Republic of China. GB50007-2011 Code for Design of Building Foundation, China Architecture and Building Press, Beijing, China, 2011, in Chinese. 